\title{
Lugar, política e simbolismo: algumas reflexões sobre Tiananmen e Zócalo
}

\author{
Place, politics and symbolism: Some reflections on Tiananmen \\ and Zócalo
}

Marcio Jose Ornat

Universidade Federal do Rio de Janeiro

\begin{abstract}
Resumo: O conceito de lugar tem sido importante para a ciência geográfica desde a década de 1970, a partir das perspectivas Geografia Humanista e Nova Geografia Cultural. Esta espacialidade pode ser definida como uma área carregada de significados, como um complexo simbólico constituído a partir de um sentimento de pertença, segurança e proteção. Também pode ser compreendido como um elemento de identidades culturais, uma maneira de ver o mundo, uma espacialidade experienciada e produzida por uma vivência prolongada. O lugar é muitas vezes constituído por saberes e fazeres e intermediado na experiência pelos símbolos. A perspectiva desta reflexão tratar o conceito de lugar a partir de dois caminhos. No caso do Tianamen e Zócalo discutimos inicialmente o conceito do lugar a partir de sua interface com a política, para em seguida tratâ-lo enquanto construído por camadas de significados.
\end{abstract}

Palavras-chave: Lugar. Política. Simbolismo.

\begin{abstract}
The concept of place has been important for geography since the 1970s, when it was introduced through the perspectives of Humanist and New Cultural Geography. Its spatiality can be defined as an area fraught with meaning, as a complex symbol that is constructed through a sense of belonging, safety and protection. It also can be interpreted as an element of cultural identities, a way of seeing the world, an experienced spatiality produced by a prolonged experience. Often places are embedded in knowledge and practices and brokered by symbols. Our perspective deals with the concept of place in two directions. First, we discuss the concept of place, in the case of Tianamen and Zócalo, as an interface with politics, and then we investigate its structure, which is built by several layers of meaning.
\end{abstract}

Keywords: Place. Politics. Symbolism. 


\section{PALAVRAS INICIAIS}

O lugar tem sido um objeto de interesse da ciência geográfica pelo menos desde a década de 1970, a partir das perspectivas Humanista e Nova Geografia Cultural. Para Staeheli (2008), o lugar pode ser definido como um contexto ou cenário, em termos relacionais, como um processo, ativo e dinâmico. O autor sugere cinco possíveis definições de lugar: o lugar como uma localização física ou local; o lugar como uma localização social ou cultural; e como um contexto; o lugar visto como construído socialmente através do tempo; e o lugar como um processo. Outras possibilidades podem ser vistas em Cresswell (2004), relacionando o lugar à paisagem, ao espaço e enquanto um caminho de compreensão. Assim, de forma geral, na Geografia as principais perspectivas relacionadas ao conceito de lugar referem-se a uma área carregada de significados, como um complexo simbólico, constituído a partir de um sentimento de pertença, segurança e proteção, colocado como um elemento de identidades culturais, como uma maneira de ver o mundo, como uma espacialidade experienciada, produzida por uma vivência prolongada, constituída por saberes e fazeres e intermediado na experiência pelos símbolos.

Neste ponto, tanto a reflexão de Hershkovitz (1993) em Tiananmen square and politics of place, como de Mandoki (1998) em Sites of symbolic density: a relativistic aproach to experience space se tangenciam no tocante à discussão que realizam sobre o conceito de lugar, mas a partir de dois caminhos distintos. A primeira faz uma discussão sobre espaço monumental e política, enquanto a segunda constitui um caminho a partir de uma interpretação da teoria da relatividade. Da mesma forma, são utilizados dois referenciais empíricos distintos, a primeira trata das políticas de lugar da Praça de Tiananmen, em Pequim, enquanto a segunda sistematiza a história da Praça de Zócalo, na Cidade do México, a partir de camadas de significado.

Assim, nosso objetivo é demonstrar, a partir deste texto, as sobreposições das duas propostas, mesmo que distintas. Mas também demonstrar a própria riqueza da distinção, pois isto valoriza a multiplicidade de perspectivas de compreensão das dimensões espaciais da vida social. Para tanto, estruturamos o texto em dois momentos, um deles demonstrando as questões que envolvem a Praça de Tiananmen e a política do lugar, para no segundo momento dissertar sobre os lugares de densidade simbólica, a partir de uma reflexão sobre a Praça de Zócalo.

\section{POLÍTICAS DE LUGAR NA PRAÇA DE TIANANMEN}

A Praça de Tiananmen é hoje o resultado de duas tradições espaciais distintas, mas interligadas. Para Hershkovitz (1993), a praça e seus monumentos foram historicamente envolvidos no conjunto simbólico de mapas de significado tanto da população quanto do Estado Chinês, assim como visto por Jackson (1989) em relação às possibilidades de interpretação do Reino de Kandy, no Sri-Lanka. Entretanto, estes mapas de significado não são homogêneos, incorporando uma tradição de dissidência, através da apropriação pelos movimentos sociais desta espacialidade, resultado da contínua dialética entre produção e apropriação.

As lutas que aconteceram na Praça de Tiananmen em 1989 demonstraram a grande força deste lugar para os movimentos políticos, tanto de afirmação quanto de contestação, na própria produção e definição desta espacialidade. Prova desta contradição, que se coloca como motor da 
dinâmica da Praça de Tiananmen, foi a imposição da estátua Deusa da Democracia, um monumento não apenas desautorizado pelo Estado Chinês, mas colocando-se como uma contestação material ao monopólio do Estado sobre a produção e significação da iconografia da Praça. Hershkovitz (1993) trata que as semanas de maio a junho, que culminaram com o confronto entre policiais e estudantes, foram muito mais que uma frente à trama política, mas de fato um contêiner de ações humanas e um terreno de práticas políticas, por meio dos quais os seres humanos recriaram sua própria história.

O conceito de lugar é uma importante ferramenta na compreensão das questões envolvendo tanto a Praça de Tiananmen com a Praça de Zócalo. O conceito de lugar foi tornado como um objeto de interesse, tanto da Geografia, como de outros cientistas sociais, incorporando o tratamento da experiência do lugar e o multifacetado significado dos lugares e paisagens. Hershkovitz (1993) demonstra que vários autores têm tratado do lugar a partir de distintas, mas interligadas perspectivas, como Cosgrove e Daniels (1988) visualizando o lugar como uma imagem simbólica ou iconográfica, Cosgrove e Jackson (1987) compreendendo o lugar como texto ou teatro, ou ainda através de Smith (1992) vendo o lugar como mito. Isso demonstra a ocorrência de uma reaproximação entre as imaginações geográficas e sociológicas, ou entre a Geografia Social e Cultural, dando relevância às complexas interações entre espaço e práticas sociais, relações estas que envolvem muitas vezes a competição, o conflito e a violência.

A sobreposição entre lugar e política não tem sido algo comum entre as publicações geográficas ou das ciências sociais. Esses trabalhos não têm atentado para o fato de que os monumentos, instituídos pelo Estado ou pelos grupos centrais nas
LUgAR, POLÍTICA E SIMBOLISMO: ALGUMAS REFLEXõES SOBRE TIANANMEN E ZÓCALO

relações de poder (FOUCAULT, 1988), são as mais visíveis manifestações concretas do poder político. Outra apreensão é que estas formas demonstram a centralidade de alguns grupos sociais no privilégio de significações e interpretações das formas criadas. Estes grupos centrais utilizam estas formas como um veículo de comunicação, a partir da socialização de um vocabulário simbólico / iconográfico. (HERSHKOVITZ, 1993).

Mesmo que as ações dos grupos estejam reservadas a apenas alguns agentes, o espaço monumental coloca-se como uma imagem que reflete os grupos sociais localizados no centro das relações de poder, ao invés de corresponder à imagem de apenas um agente (LEFEBVRE, 1991). Hershkovitz (1993) argumenta que embora Lefebvre defenda o fato de que todos os membros de uma coletividade possuem uma consciência social que é incorporada nos espaços monumentais, esta incorporação se faz apenas sob uma aceitação generalizada do poder.

A própria história nos mostra que os monumentos têm sido os mais visíveis produtos do poder hegemônico e de seus produtores para dominar o espaço, como por exemplo, a igreja e o Estado. Entretanto, como afirmado por Foucault (1988), onde há poder também há resistência, e este não é exterior ás próprias relações de poder. Assim, as propriedades dos espaços monumentais tornam-se sociais, pois cada espacialidade pode ser utilizada de maneiras distintas, ou até mesmo contraditórias dos objetivos dos construtores ou proprietários, no ato da construção das formas. Mas, se existe a possibilidade da existência da contradição, Hershkovitz (1993) também defende a tese de que este uso pode estar integrado ao próprio simbolismo e a iconografia do lugar, ficando compreendido como uma espacialidade que é produzida através da política, como 
algo imposto ou resultado de processos políticos acumulativos e dialéticos. $\mathrm{Na}$ maioria das vezes é através de dissidentes ideológicos, de resistências políticas ou culturas periféricas que a apropriação do espaço dominado ocorre, colocando-se este ato político em uma expressão espacial.

Hershkovitz (1993) aponta que vários trabalhos têm tratado dos usos subversivos do lugar e de outros símbolos do poder. Essa ação, visando à subversão, tem demonstrado as atitudes empregadas por vários grupos na contestação do centro das relações de poder, como visto por Hall (1980). Cada uma destas ações envolve a apropriação de artefatos e significações relacionados à cultura dominante, a centralidade das relações de poder, dando-se no caminho da produção de novos significados (COSGROVE \& JACKSON, 1987). Como nas afirmações de Certeau (1984), se o poder hegemônico relaciona-se a dominação de uma espacialidade, onde seria então o lugar daquilo que é periférico nas relações de poder, que não possui nenhuma propriedade? Este seria o espaço do outro, na contestação desta centralidade. Fica como objetivo o contraste da prática espacial daqueles que detém o poder, daqueles que desafiam a existência deste. Isto mostra a necessidade do espaço nas relações de poder, por mais indireta e rarefeita que esta espacialidade nos pareça.

Temos centro e periferia das relações de poder, com características distintas. Então, as ações dos indivíduos/grupos localizados nestas posições sociais são também distintas. As estratégias referem-se às práticas sociais daqueles que estão localizados no centro das relações de poder, enquanto a tática coloca-se como o espaço do outro, relacionado a periferia destas mesmas relações (CERTEAU, 1984). Devido a esta associação histórica de luta e resistência na produção e apropriação do espaço, alguns lugares tornam-se mais significativos e simbólicos na ordem dominante que outros, como exemplo, Tiananmen e Zócalo

O espaço monumental coloca-se como um condensador social. Assim, quando os movimentos políticos dissidentes se apropriam destes espaços, automaticamente tomam posse do poder condensado nestes espaços. Portanto, a geografia simbólica da cidade é a representação do poder político e das relações sociais em seus constantes movimentos (HERSHKOVITZ, 1993). Quando as organizações de revolta transformam-se em revolução, estas criam uma nova ordem espacial, construindo sobre este e investindo com novos significados. Pelo fato da não existência de um espaço vazio no qual construam-se significados, o espaço de uma nova conquista é o espaço da conquista do outro; suas características não são obliteradas, mas apropriadas e transformadas.

Tais relações de contradição e conflito visualizam-se, para Hershkovitz (1993), a partir das duas tradições espaciais da Praça de Tiananmen: a primeira se relaciona a um política ortodoxa de poder, simultaneamente política e religiosa, que é marcada e remarcada por uma elite. Esta tem um objetivo consciente de criação de um espaço simbólico, tendo a oportunidade de acomodar o símbolo. E mesmo com as mudanças de 1911 e 1949, a ortodoxia continua a se inscrever nos remanescentes dos monumentos, buscando influenciar o significado dos seus usos atuais; a segunda tradição coloca-se a partir do início do século XX, tendo superficialmente como símbolo o controle da praça, mas a partir de outra escala, o próprio controle do Estado Chinês. Sobre isto, a praça coloca-se como um objeto físico de luta e transformação, mas também como um produto deste mesmo processo histórico. É a partir disto que o movimento estudantil Chinês pode ser compreendido. Mas também auxiliando na compreensão dos motivos da ferocida- 
de com a qual a praça foi reclamada pelo Estado.

Buscando fazer uma compreensão da praça, Hershkovitz (1993) periodiza a constituição de Tiananmen. Todavia, vemos ao invés de períodos de tempo, uma sobreposição de camadas de acontecimento, ou como nas palavras de Mandoki (1998), uma justaposição de camadas de significado. Assim, a praça é composta por cinco camadas de densidade simbólica, a saber: a geografia simbólica da praça de Tiananmen, Tiananmen como um espaço público, a ortodoxia pós-revolucionaria de Tiananmen, a transformação contemporânea de Tiananmen, e as lutas pela praça de Tiananmen em 1989.

O início da primeira camada de densidade simbólica da praça de Tiananmen ocorre no final do séc. XIV, quando a dinastia Ming vence a dinastia Mongol, estabelecendo para si seu próprio local imperial. O nome dado a este local foi Beijing, ou Capital do Norte, estando o poder central do império localizado no Palácio Imperial, na Cidade Proibida.

Como levantado por Hershkovitz (1993), a cidade foi construída a partir da cosmografia ortodoxa chinesa, como um símbolo cósmico e mágico que se colocava em uma forma concreta. Ela tinha a forma retangular orientada pelos pontos cardeais. Tinha uma organização possuindo uma cidade interior (Cidade Imperial), e uma cidade exterior, com uma ligação através do portal de Tiananmen. Esta organização era a concretização de uma ordem hierárquica do espaço, onde a sacralidade diminuía com a distância do centro. Ao sul do portal existia um espaço semi-público em forma de " $T$ ", que era o precursor da Praça de Tiananmen.

Como afirmado pela autora, esse espaço era uma área gradual entre o interior e o exterior, entre o sagrado e o profano, entre o imperial e o comum. Um continuum de diminuição da sacralidade. Este era um espaço onde se realizavam os rituais de Estado, as revisões militares, as oferendas rituais, e as proclamações do imperador. O tempo de formação desta camada de densidade simbólica foi do fim do séc. XIV ao séc. XIX, quando da desintegração da Dinastia Qing. Neste momento, uma nova camada começa a se constituir. Hershkovitz (1993) aponta que neste evento, a Cidade Proibida foi ocupada por estrangeiros armados. Entretanto, as transformações morfológicas aconteceram na metade do séc. XX.

Inicialmente, com a revolução de 1911, a cidade perdeu seu papel como local imperial. Esta revolução foi dirigida por Sun Yat-Sen, o qual estabeleceu a República da China. Com estas transformações, Tiananmen agora era aberta ao publico, mas o arco de Tiananmen recebeu o simbolismo revolucionário chinês. Também fora aberta uma rua de leste a oeste, transformandose a praça em um mercado informal e de recreação. A praça transforma-se de um espaço controlado e fechado, que simbolizava e incorporava a autoridade e a ortodoxia do Estado Chinês, para um espaço aberto, no qual novas funções heterodoxas tomavam lugar. Esta abertura, metaforicamente, também foi orientada a uma vivência espacial que até agora não existia.

Na primeira manifestação em 1919, a Praça foi tomada por três mil estudantes que protestavam contra a resposta passiva do governo chinês de alienação do território pelo Tratado de Versailles. Seu tom era anti-imperialista e anti-governista. Após este fato, mais doze protestos antigovernistas ocorreram na capital nos anos de 1920, 1930 e 1940. Estes eventos culminaram em muita violência entre estudantes e policiais, colocando-se como um choque entre o patriotismo dos jovens intelectuais chineses e o autoritarismo no moderno 
Estado Chinês. Mesmo que agora o espaço fosse aberto, a hierarquia tradicional de um espaço organizado espelhava a completa impenetrabilidade tradicional do poder político e de seu simbolismo criado. E foi em relação a este espaço que estes grupos oposicionais articularam suas agendas políticas.

A somatória destes eventos, com a Revolução Comunista, ocorrida em 1949, inaugura uma nova camada de densidade simbólica na Praça de Tiananmen. O novo regime instalado no poder a partir da revolução tinha por herança tanto os monumentos da cidade proibida, como Tiananmen, que ainda simbolizava o papel central da hegemonia e ideologia do Estado Chinês. Como frisado por Hershkovitz (1993), o objetivo deste regime era uma mescla de apropriação e reconciliação destes simbolismos contraditórios, produzindo um caminho de auto-legitimação e criando uma própria linguagem relacionada à sua hegemonia sobre a nação chinesa. Prova disso foi a escolha da Praça de Tiananmen como o símbolo nacional da República Popular da China.

Após esta data, Tiananmen foi ampliada e novos monumentos foram postos. Todavia, os velhos elementos permaneceram, sendo reinterpretados em direção a um apelo patriótico e a uma consciência proletária. As transformação morfológicas da Praça estavam relacionada à colocação de um enorme retrato de Mao Tse-Tung, a retirada das árvores para acomodar as multidões, uma ampliação dos braços do " $\mathrm{T}$ ", dando-se o nome de Chang Boulevard, a implantação da Grande Muralha do Povo, o Museu da Revolução Chinesa e o Memorial dos Mártires da Revolução Chinesa (Monumento dos Heróis do Povo), no centro da praça, olhando para Tiananmen.

A Praça combinava um sentido de abertura e inclusão, com um elemento de intimidação. Este continuava a ser um espaço de ritual, mas agora não excluindo: uma espacialidade das massas, criada para elas. Isto se coloca com tanta força, que após 1949, todos os feriados e celebrações importantes eram comemoradas na Praça, instituindo-se assim um espaço da ufania. Outro fato importante levantado por Hershkovitz (1993) é que quando da morte de Mao Tse-Tung, este não foi enterrado no cemitério dos heróis revolucionários, que se localizava no subúrbio, mas na Praça. E com sua morte e sepultamento, a Praça se completa (ver Figura I abaixo), com o Museu da História Revolucionária, o Grande Muro do Povo, o Memorial dos Mártires, o Mausoléu de Mao Tse-Tung, e seu retrato sobre o portal de Tiananmen.

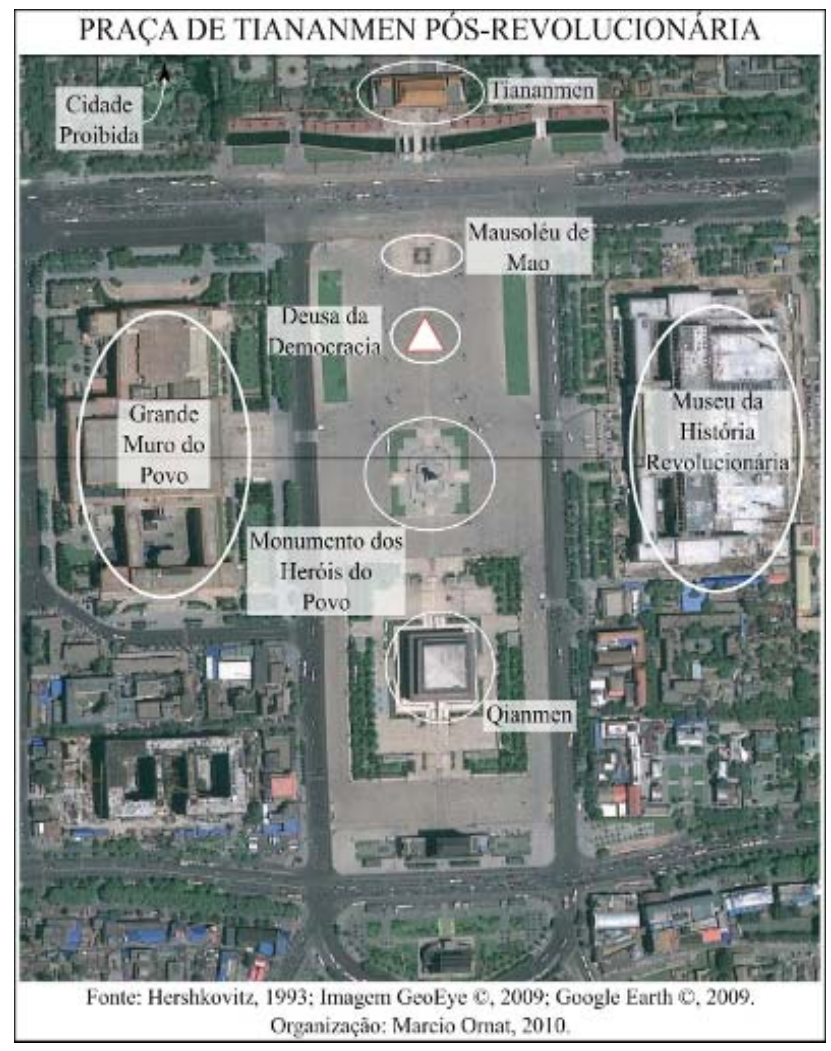

Com toda esta sobreposição de acontecimentos sobre uma mesma espacialidade, Tiananmen coloca-se para além de um texto a ser lido. Incorporando essa característica, a Praça torna-se um espaço para 
a ação. Se a praça reverencia o Estado Chinês e os feitos do Partido Revolucionário Chinês, uma espacialidade carregada de significado, com a morte de Zon Enlai e Mao, nasce um movimento de protesto que converge para a Praça.

Em dois dias de manifestação são vistos dois milhões de manifestantes, e no confronto com policiais, mais de cem pessoas são mortas e milhares são presas. Este evento ocorrido em 5 de abril de 1976 se apresenta como um movimento contra-revolucionário, que desafiava a ortodoxia revolucionária concretizada em Tiananmen.

Este protesto se apropriou do espaço do outro, reivindicando uma autêntica tradição revolucionária. Os manifestantes investiram na Praça novas imagens simbólicas que podiam ser ancoradas nas manifestações de oposição de 1919 e 1925. Esta ação criou um novo horizonte de significados para a Praça. Mas como de regra, o Estado reclama para si Tiananmen, demonstrando tanto um uso exclusivo para sua expressão política, como proclamando a sua interpretação da geografia simbólica da praça.

Esta camada, que se colocou como o desvio contemporâneo da Praça de Tiananmen, ativou o início da formação da última camada de densidade simbólica de Tiananmen, estruturada a partir dos conflitos tendo por objeto a própria praça. O mais importante nesta compreensão é de que o cerne principal do conflito estava relacionado às duas interpretações do significado da Praça de Tiananmen, conflitos que ocorreram em 1978-79 / 1986-87 / 1989.

Estes conflitos envolviam lutas espaciais sobre a ocupação e controle da praça, sendo a consciência espacial um elemento de ambos os lados na luta pelo espaço. E no evento final, após o controle do espaço, os estudantes transformaram a praça, tomando os monumentos e adicionando seu próprio monumento, a Deusa da Democracia. Os estudantes puderam usar a geografia simbólica do lugar incorporando seus próprios rituais políticos (HERSHKOVITZ, 1993).

Na visão oficial, a praça era uma espacialidade sagrada. Portanto, na interpretação do Estado, a ocupação estudantil era um uso ilegítimo deste espaço sagrado. Após duas semanas de confronto, o Estado tomou para si a praça, celebrando a sua vitória, e fazendo-a novamente um 'espaço público'.

Contudo, os espaços públicos nunca podem ser plenamente fechados, obrigando assim a uma multiplicidade de significados e usos (HERSHKOVITZ, 1993). E isso produz uma tensão constante entre dominação e apropriação do espaço público. Os acontecimentos de 1989 consolidaram mais uma camada de densidade simbólica, que fora incorporado ao horizonte de significados da Praça de Tiananmen, demonstrando o poder da justaposição entre política e lugar na definição e transformação de espaços.

\section{LOCAIS DE DENSIDADE SIMBÓLICA E ZÓCALO}

Certos objetos e eventos aparecem para alterar a configuração do espaço. Esses elementos, colocados em um ponto, produzem um fenômeno de alta densidade espacial. Como dissertado por Mandoki (1998), esta hierarquia de significados é determinada pela história e pela qualidade dos eventos que ocorreram neste determinado local. A autora não utiliza o exemplo da Praça de Tiananmen, alinhando-se perfeitamente a sua reflexão. Seus recortes referem-se ao Monte Moriá, a Caaba em Meca, e Tenochtitlán, na Cidade do Méxi$\mathrm{co}$, mais especificamente.

Esses exemplos são uma metáfora 
perfeita da construção do significado simbólico do lugar, pois as localizações humanas não são apenas determinadas pelas condições de suas práticas cotidianas de reprodução social, como proximidade de recursos materiais ou uma posição estratégica de ataque ou defesa, mas também por camadas de significado que são enriquecidas através do tempo, num processo diacrônico. Um lugar não seria apenas formado pelo conjunto de elementos geográficos e de arquitetura, mas construído e configurado simbolicamente com imaginários sociais, formando mapas de significado dentro de diversos complexos de organização simbólica.

Mandoki (1998) descreve o Monte Moriá como um destes lugares de densidade simbólica (ver a Figura II abaixo). Segundo a Bíblia, este era o lugar que Abraão quase sacrificou Isaac. Também foi mais tarde a localização do templo que seria da 'Arca da Aliança', construído pelo Rei Salomão, até que o Rei Babilônico Nabucodonosor II a destruiu em 586 a.C. Reconstruído no mesmo local pelo Rei Heródoto (40 - 4 a.C.) e destruído novamente pelos Romanos em 70 d.C. Quinhentos anos depois, este foi o ponto exato de ascensão de Maomé aos céus, em 8 de junho de 632 d.C. Este lugar foi, trinta anos depois, a localização da mesquita Domo de Ouro. Consequentemente, esta espacialidade é um elemento de disputa entre muçulmanos e judeus hodiernamente.
Outro exemplo utilizado por Mandoki (1998) relaciona-se a Caaba, em Meca. Este é o maior santuário Islâmico do mundo, localizado no pátio da grande Mesquita. O local coloca-se como um lugar de densidade simbólica devido ao fato de que, segundo o Al Corão, foi construída por Adão e reconstruída por Abraão, no entorno de uma rocha negra que teria sido dada a Ismael pelo anjo Gabriel. Este seria um local utilizado pelas divindades pagãs, até que Maomé iniciou sua pregação aos Mecanos e reconsagrou o local a Alá. Sua importância é tão grande que pelo menos uma vez na vida cada muçulmano tem que visitar a Caaba e ali fazer suas orações.

Esses locais não seriam os únicos possíveis lugares de densidade simbólica,

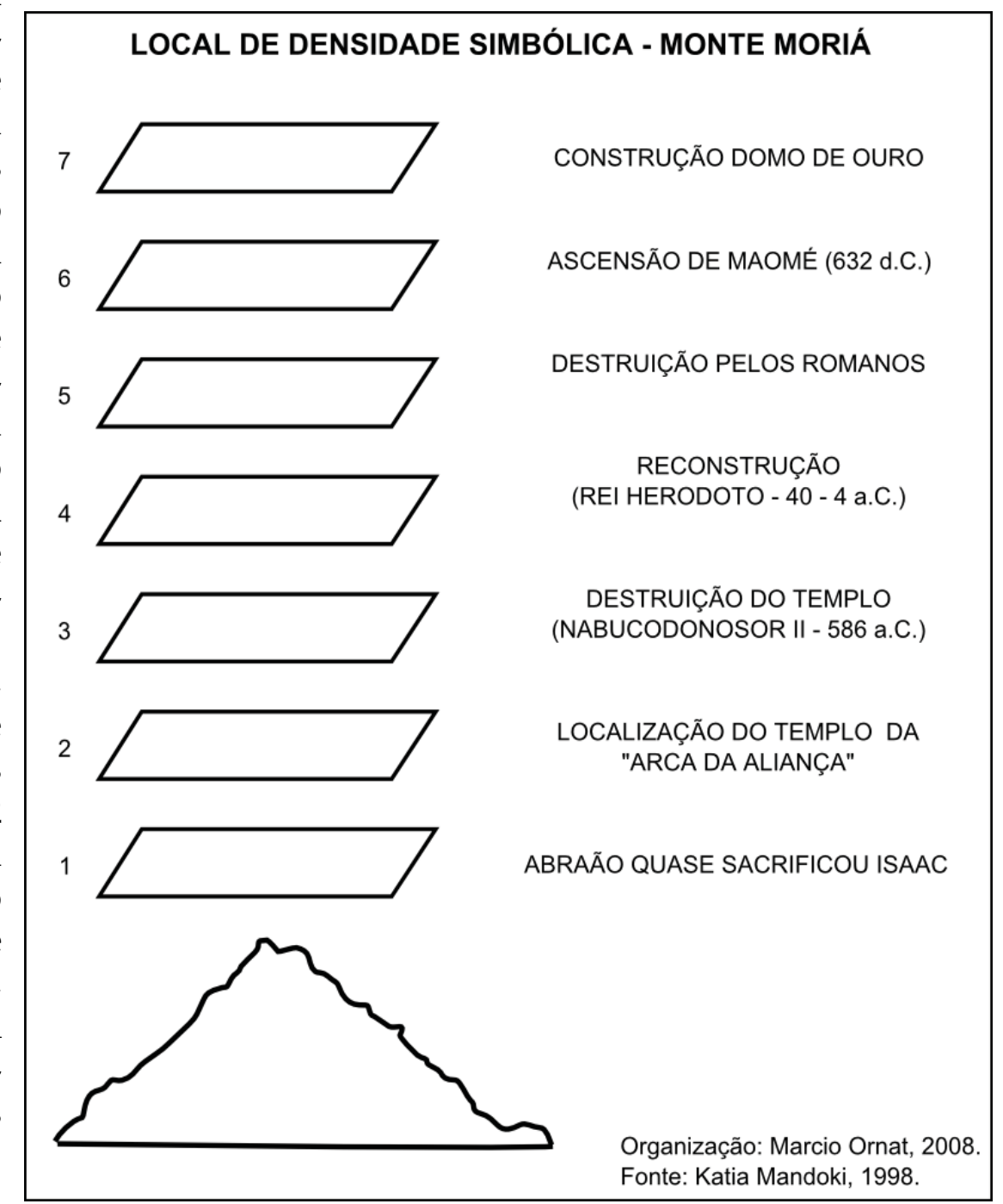


colocando-se ao lado deles Tenochtitlán. Utilizando-se da formação asteca e de sua colonização, Mandoki (1998) se propõe construir uma cartografia simbólica, salientando a especificidade de construção e experimentação de características específicas de um lugar. As quatro camadas de significado simbólico propostas pela autora são: O Local Mitológico, O Local Imperial ou Teocalli, O Local de Afirmação Colonial e O Local Executivo.

Existem seis lendas que orbitam sobre a origem de Tenochtitlán, afirmando sua posição enquanto local mitológico. A primeira refere-se ao fato de que os Astecas haviam migrado para Aztlan por ordem de seus deus Huitzilopochtli. O local seria marcado por uma águia pousada sobre um cactos específico, o Opuntia. Na segunda lenda, o sacerdote Asteca Cuauhtlequetzi mata o sacerdote Copil Malinalcan, arranca seu coração e manda que seu assistente o plante em meio a plantas de tule. No local nasce o cacto, no qual a águia estava em pé. Este seria o local de fundação de Tenochtitlán, em ilhotas em meio ao lago Texcoco. Na terceira lenda a águia havia sido encontrada em pé sobre o Opuntia, o qual estava coberto por excremento da ave. Na quarta lenda a águia havia sido encontrada em pé sobre o Opuntia, o qual estava coberto por restos de animais que a ave havia comido. Na quinta lenda a águia havia comido uma serpente sobre o cacto. E na sexta lenda, na ilustração de Mendoza Codex, a águia é vista sobre o Opuntia. Mas em todas as lendas, como salientado por Mandoki (1998), o indicador do local é a somatória da águia mais o Opuntia.

Existe a fusão de duas lendas: a do comando e a do sacrifício, havendo uma conjugação de dois níveis de significado, a águia - enquanto uma figura celestial, mas também uma figura político-militar, e o Opuntia - uma terrena homenagem a uma das espécies da natureza. Estas ima- gens não apenas dotam o local com grande significado, mas dão coerência ao mundo de opiniões dos astecas.

Além da espacialidade, a temporalidade é um evento altamente significativo para os astecas. Mas indo além dos dois, a fusão entre espaço e tempo traz sentido ao cotidiano asteca, pois o local e o momento em que a águia pousou no cacto alterou significativamente a história do local, ao ponto da cidade visualizada por Hernan Cortez ser comparável a Cevilha e Córdoba (MANDOKI, 1998).

Havia uma fonte em Tenochtitlán, em que, segundo a lenda, existia uma nascente de água que tinha se transformado em sangue. Nesse local foi construído uma praça e um templo para o deus Huitzilopochtli. Duzentos anos depois, neste mesmo local foi construída uma câmara, encontrada durante a fundação do Palácio Nacional da Cidade do México, chamada Teocalli. Havia uma ilustração de uma águia sobre o Opuntia, vertendo água no bico da águia, a qual se transformava em sangue, que era oferecido. Isto indica o local onde a águia deveria ter pousado, mais tarde tornandose o Palácio de Montezuma e o templo do deus Huitzilopochtli.

Toda a imagem, na interpretação de Mandoki (1998), funciona como um dispositivo metafórico e retórico que indicava que aquele era o local da comunidade asteca. Local onde os astecas alimentariam seu deus Huitzilopochtli e fariam cumprir o mundo. Neste local é construído uma praça que se tornou um ponto radial a partir do qual todos os templos e palácios do império foram construídos. Todo o cotidiano asteca estava relacionado à praça, sendo um lugar de celebração religiosa e o segundo mercado de toda América Central.

Em 1521, Tenochtitlán foi destruída pelos conquistadores espanhóis. E Cortez escolhe o mesmo local como a nova capital 
da Espanha. Seu motivo foi a importância do significado simbólico acumulado no local. Mandoki (1998) aponta que a praça é mantida no mesmo local e continua a servir como espacialidade para cerimônias religiosas, civis e como o principal mercado. Em 1529, Cortez transforma em sua residência o mesmo local que Montezuma residia. E novamente, a densidade simbólica deste local foi essencial para Cortez, declarando simbolicamente a substituição do poder de Montezuma. Esta propriedade é requerida pelo imperador da Espanha e com a morte de Cortez, as principais instituições coloniais são transferidas para a residência de Montezuma. Tal fato afirma-se pela criação do Palácio do ViceReinado sobre o mesmo local do palácio de Montezuma. Tal camada se finaliza com a implantação de um relógio substituindo a ordem simbólica da águia e do opuntia, no Teocalli.

Após sessenta e três vice-reinados, uma guerra anti-colonial, duas regência do império, o primeiro império de Augustin Itubide, o primeiro presidente da República, e a revolução de 1910 quase ter começado ali, houve uma mudança simbólica, mas o local foi mantido, mantendo-se constante. O Teocalli foi substituído pelo relógio, e este substituído pelo Sino da República Independente. Até hoje este sino é usado uma vez por ano, às onze horas do dia quinze de setembro, data do início da luta pela independência em 1810 (MANDOKI, 1998).

Após 1910, outro elemento é adicionado ao universo simbólico de Tenochtitlán: Diego Rivera pinta um mural na escadaria do Palácio do Governo, como a versão oficial da história do México. O tema principal do seu mural era o espaço - tempo: do tempo pré-hispânico da Cidade do México para o futuro. São vistos o Teocalli, o Relógio Colonial e o Sino da Independência. O mural captou a ideia de tempo, precisamente como um lugar de densidade simbólica.

A principal praça da cidade de Tenochtitlán torna-se durante o século XVI a Colonial Zócalo, e além da principal praça da cidade, o principal centro do país. Foi na praça que a grande Catedral Metropolitana foi construída, foi o local dos enforcamentos da Inquisição, das principais cerimônias civis e religiosas e o local de comércio e manifestações.

Mandoki (1998) finaliza sua discussão afirmando que a Cidade do México é colocada em muitos sentidos, como o local da profecia, o local do império mais poderoso da América Central, o local de massacres na invasão espanhola, o local do vice-reinado, o local do centro do poder político e o local de uma das mais populosas cidades do planeta. Têm-se um conjunto de práticas políticas, históricas e todo um significado religioso sendo catalisado no sentido de um único lugar. Algumas transformações são passíveis de acontecimento, como relacionadas à política, a religião e a língua, mas o local tem permanecido através dos tempos.

\section{PALAVRAS FINAIS: LUGAR, CULTURA E MAPAS DE SIGNIFICADO}

Jackson (1989) tem afirmado que as culturas emergem como o resultado de contradições políticas e econômicas. Não reduzindo tudo ao econômico - político ou ao efêmero, a cultura relaciona-se com a negociação de significados entre relações de dominação e contestação, em uma mediação entre economia e política. Então a cultura se refere aos códigos com os quais os significados são construídos, encaminhados e contestados. Para o autor, como na metáfora utilizada pelos integrantes do Center for Contemporary Cultural Studies, as culturas são mapas de significado que 
intercedem em nossa compreensão do mundo, não é uma instância pairando sobre a cabeça dos homens, mas fazendo-se concreta a partir das formas de organização social. Assim, cada conjuntura, tanto relacionada à Praça de Tiananmen, quando a Praça de Zócalo, se faz legível a partir da sua lugaridade. Qualquer acumulo de camadas de significado se faz inteligível a partir das circunstâncias valoráveis e pertinentes na estrutura social. Tais circunstâncias colocam-se a partir de conjuntos de opiniões dominantes, sendo naturalizadas como parte do cotidiano, tanto no painel pintado por Diego Rivera, transcrevendo na escadaria do Palácio do Governo a 'versão oficial' da história do México, como no discurso do Estado Chinês, tratando a praça de Tiananmen como uma espacialidade sagrada para 'todos'. Entretanto, fugindo da ideia de ideologia hegemônica opressiva, os significados não são apenas impostos, mas também negociados, contestados e registrados a partir de várias versões, pois as culturas normalmente tidas como subordinadas, se apropriam dos recursos orientados a um fim, transformando-os em outro, como em Tiananmen. A cultura não é apenas um produto que tem uma expressão espacial, mas uma espacialidade constituída e constituinte.

As duas reflexões apontam que tanto Tiananmen quanto Zócalo são construções significadas simbolicamente, mas a partir de duas possibilidades: Tiananmen é um produto de duas interpretações geográficas, uma relacionada ao Estado chinês, e outra referente aos grupos dissidentes. De forma distinta, Zócalo estrutura-se a partir do mito como um auxiliador na construção de mapas de significado de Tenochtitlán. Mandoki (1998) não privilegia o conflito das interpretações. Do contrário, dá a entender que existe uma justaposição de interpretações, ou camadas de significado não conflitantes. Em Tiananmen, o que transparece é a imposição de uma leitura de mundo, a colocação de um espaço da ufania, de apenas uma forma de construção de significado, de forma impositiva, culminando na utilização da força, sobre outras possíveis interpretações.

Tanto a proposição de Hershkovitz (1993) como a de Mandoki (1998) são de fundamental importância. Mesmo de forma periférica valorizam a especificidade, fugindo das metanarrativas tão caras ao pensamento ocidental. As duas leituras conjugadas abrem a possibilidade de uma multiplicidade de leituras na compreensão da ação humana sobre a superfície da Terra.

\section{REFERÊNCIAS}

CERTEAU, Michel de. The practices of everyday life. Berkeley: University of California Press, 1988.

COSGROVE, Denis; DANIELS, Stephen. The iconography of landscape: essays on the symbolic representation, design and use of past environments. Cabridge: Cambridge University Press, 1988.

COSGROVE, Denis; JACKSON, Peter. New direction in cultural geography. Area, v. 19, n. 2, p. 95-101, 1987.

CRESSWELL, Tim. Place: a short introduction. Malden, USA: Blackwell Publishing, 2004.

FOUCAULT, Michel. História da sexualidade I: a vontade de saber. Rio de Janeiro: Graal, 1988.

HALL, Stuart. et al. Culture, media, language: working papers in cultural studies 1972-1979. London: Hutchinson, 1980.

HERSHKOVITZ, Linda. Tiananmen square and politics of place. Political Geography, v. 12, n. 5, p. 395-420, set. 1993.

JACKSON, Peter. Maps of meaning: an introduction to cultural geography. New York: Routledge, 1989. 
Marcio Jose Ornat

LEFEBVRE, Henri. The production of space.

Oxford: Blackwell, 1991.

MANDOKI, Katya. Sites of symbolic density: a relativistic approach to experienced space. In: LIGHT, Andrew; SMITH, Jonatham M. Philosophies of place. New York: Rowman \& Littlefield Publishers, 1998.

SMITH, Neil. New city, new frontier: the lower east side as wild, wild west. In: SORKIN, Michel (Org.). Variations on a theme park: the new american city and the end of public space. New York: Noonday Press, 1992.

STAEHELI, Lynn A. Place. In: AGNEW, John; MITCHELL, Kataryne; TOAL, Gerard. A companion to political geography. Malden, USA: Blackwell Publishing, 2008.

Recebido em 15/08/2009

Aceito em 17/10/2009 